ECONOMICA

Journal of Economic and Economic Education Vol.3 No.2 (234 - 242)

\title{
PENGARUH KARAKTERISTIK BUDAYA ORGANISASI TERHADAP ORGANIZATIONAL CITIZENSHIP BEHAVIOR (Studi Kasus Rumah Sakit Umum Citra Bunda Medical Centre Padang)
}

\author{
Mareta Kemala Sari \\ Dosen Program Studi Pendidikan Ekonomi STKIP- PGRI Sumbar \\ Jl. Gunung Pangilun No.1, Padang Sumatera Barat \\ Email: cha.delly@yahoo.com \\ Ika Hajriani \\ Dosen Program Studi Manajemen Sekolah Tinggi Ilmu Ekonomi Perdagangan \\ Jl. Dr. Hamka No. 232, Padang Sumatera Barat \\ Email: ikahajriani@yahoo.com
}

submited: 2015.01.27 reviewed:2015.02.29 accepted: 2015.04 .26

http://dx.doi.org/10.22202/economica.2015.v3.i2.259

\begin{abstract}
This study aimed to analyze the influence of organizational culture characteristic measured from the professionalism, the distance of the management, trust in colleagues, regularity, hostility and integration of the employees of the organization Behavior / Organizational Citizenship Behavior (OCB) employees Citra Bunda Hospital Medical Centre Padang. OCB important to investigate the behavior of health workers due to the organization of health workers led to the success of public health care. All employees RSU Citra Bunda Medical Centre Padang many as 177 people are in this study population. The results showed that there was a significant positive influence and not variable professionalism of 0.184 with a significant value of $0.086>0.05$ and a variable distance from the management of a significant value of 0.089 with $0.286>0.05$ on OCB, there is a positive and significant impact on the trust variable associates amounted to 0467 with a significant value of $0.028<0.05$ against the $O C B$, there is positive and not significant at .093 with variable regularity significant value for $0662>0.05$ on $O C B$, there is a positive and significant influence amounted to 0.526 hostility variable with significant value $0.045<0.05$ against the $O C B$ and there are positive influence and no significant integration variable of 0.207 with significant
\end{abstract}

\begin{abstract}
Abstrak
Penelitian ini bertujuan untuk menganalisis pengaruh karakteristik budaya organisasi yang diukur dari profesionalisme, jarak dari manajemen, percaya pada rekan, keteraturan, permusuhan dan integrasi terhadap Perilaku organisasi karyawan/Organizational Citizenship Behavior (OCB) karyawan RSU Citra Bunda Medical Centre Padang. OCB penting untuk diteliti pada tenaga kesehatan dikarenakan perilaku organisasi tenaga kesehatan berujung pada keberhasilan perawatan kesehatan masyarakat. Seluruh karyawan RSU Citra Bunda Medical Centre Padang sebanyak 177 orang merupakan populasi dalam penelitian ini. Hasil penelitian menunjukkan bahwa terdapat pengaruh positif dan tidak signifikan variabel profesionalisme sebesar 0,184 dengan nilai signifikan sebesar 0,086>0,05 dan variabel jarak dari manajemen sebesar 0,089 dengan nilai signifikan sebesar 0,286>0,05 terhadap OCB, terdapat pengaruh positif dan signifikan variabel percaya pada rekan sebesar 0.467 dengan nilai signifikan sebesar 0,028<0,05 terhadap OCB, terdapat pengaruh positif dan tidak signifikan variabel keteraturan sebesar 0,093 dengan nilai signifikan sebesar 0.662>0,05 terhadap OCB, terdapat pengaruh yang positif dan signifikan variabel permusuhan sebesar 0,526 dengan nilai signifikan 0,045<0,05 terhadap OCB dan terdapat pengaruh yang positif dan tidak signifikan variabel integrasi sebesar 0,207 dengan nilai signifikan 0,338>0,05 terhadap $O C B$.

Keywords: organizational culture, Organizational Citizenship Behavior (OCB), RSU Citra Bunda Medical Centre Padang
\end{abstract}




\section{PENDAHULUAN}

Sumber daya manusia dipandang sebagai asset perusahaan yang penting, karena manusia merupakan sumber daya yang dinamis dan selalu dibutuhkan dalam setiap proses produksi barang maupun jasa. Sumber daya yang potensial harus mampu mengatasi perkembangan dan kemajuan teknologi untuk menghasilkan produk maupun jasa yang up to date untuk kebutuhan organisasi atau perusahaan. Setiap organisasi atau perusahaan akan menyusun struktur organisasi yang memungkinkan perusahaan memiliki sumber daya manusia yang berkualitas dan kompetitif, sehingga organisasi atau perusahaan mendapatkan output kinerja sesuai yang diharapkan.

Namun bukan hal yang mudah untuk mendapatkan sumber daya manusia yang berkualitas dan kompetitif. Menurut data dari United Nation For Development Program (UNDP) 2013, tentang Human Development Index (HDI) menunjukkan Indonesia menduduki peringkat 121 dari 187 negara. HDI Indonesia naik 3 peringkat dibanding tahun sebelumnya yang menempati posisi 124 dari 187 negara di dunia (http://wartaekonomi.co.id) mengalami peningkatan, sepantasnyalah Indonesia tetap bekerja keras meningkatkan pengembangan sumber daya manusia.

Organisasi pada umumnya percaya bahwa untuk mencapai keunggulan harus mengusahakan kinerja individual yang setinggi-tingginya, karena pada dasarnya kinerja individual mempengaruhi kinerja tim atau kelompok kerja dan pada akhirnya mempengaruhi kinerja organisasi secara keseluruhan. Kinerja yang baik menuntut perilaku karyawan yang diharapkan oleh organisasi. Perilaku yang menjadi tuntutan organisasi saat ini adalah tidak hanya perilaku inrole, tetapi juga perilaku extra role. Perilaku extra role ini yaitu perilaku dimana karyawan melakukan pekerjaan yang secara formal bukan syarat dari pekerjaannya. Perilaku ini dikenal sebagai Organizational Citizenship Behavior (OCB). OCB merupakan istilah yang digunakan untuk mengidentifikasi perilaku karyawan sehingga dia dapat disebut anggota yang baik. Karyawan yang baik (good citizen) cenderung akan menampilkan OCB didalam organisasinya. Organisasi tidak akan berhasil dengan baik atau tidak akan bertahan apabila tidak ada anggotanya yang bertindak sebagai good citizen (Markoczy \& Xin, 2002:1).

Rumah sakit adalah suatu organisasi yang unik dan kompleks karena di dalam rumah sakit terdapat banyak institusi yang padat karya dengan berbagai sifat, ciri, serta fungsi yang khusus dalam proses menghasilkan jasa medis dan mempunyai berbagai kelompok profesi dalam pelayanan rumah sakit (Boekitwetan, 1997 dalam Muluk 1999:1). Berbagai kelompok profesi ini akan menghasilkan perilaku individu dan perilaku kelompok yang pada akhirnya menghasilkan perilaku organisasional dalam melaksanakan tugas dan fungsinya.

Rumah sakit dihadapkan pada upaya mampu melakukan pengelolaan terhadap sumber daya manusia yang ada karena sumber daya ini semakin besar peranannya bagi kesuksesan organisasi dan merupakan pelaku dari semua kegiatan dan aktivitas yang nyata. Upaya pengelolaan yang dilakukan rumah sakit dapat dilakukan dengan memberikan pemahaman terhadap sumber daya manusia yang ada di rumah sakit yang membentuk nilai, kepercayaan, dan sikap-sikap atau dikenal dengan budaya organisasi untuk menyesuaikan diri dengan perubahan dan perkembangan eksternal dan integrasi terhadap kekuatan internal rumah sakit (Muluk, 1999:1). Organ (1995:89) dalam Zurasaka (2008:46), mengemukakan bahwa budaya organisasi mempengaruhi OCB.

Budaya organisasi merupakan normanorma dan nilai-nilai yang mengarahkan perilaku anggota organisasi, dimana setiap anggota akan berperilaku sesuai dengan budaya yang berlaku agar diterima oleh lingkungannya (Luthans:2002:122). Penelitian yang dilakukan oleh Brahmasari (2008) yang dilakukan pada kantor Samsat Manyar di Surabaya menemukan bahwa 
iklim organisasi sebagai dimensi dalam budaya organisasi berpengaruh signifikan terhadap OCB, yang artinya persepsi dan kegiatan-kegiatan yang dilakukan para anggota organisasi di dalam organisasinya mempengaruhi anggota organisasi tersebut melakukan OCB

Untuk mencapai kondisi budaya kerja yang baik, dibutuhkan semangat kerja yang mengarah pada good citizenship. Artinya good citizenship akan terwujud apabila anggota organisasi memiliki OCB. Jika OCB telah terbentuk, ini akan memudahkan pihak manajemen untuk meletakkan dan menempatkan karyawan sesuai karakteristik tugasnya yang diduga akan meningkatkan efektivitas organisasi. Penelitian perilaku ekstra role ini juga telah dilakukan oleh beberapa peneliti pada berbagai perusahaan diantaranya sebagai berikut:

Tabel 1. Literature Review

\begin{tabular}{|c|c|c|c|c|c|}
\hline No & Judul & Penulis & Variabel & Hasil & Alat analisis \\
\hline 1. & $\begin{array}{l}\text { Pengaruh tingkat } \\
\text { kecerdasan emosi } \\
\& \text { sikap pada BO } \\
\text { terhadap } \\
\text { organizational } \\
\text { citizenship } \\
\text { behavior (OCB) }\end{array}$ & $\begin{array}{l}\text { Hardiningtyas } \\
(2005)\end{array}$ & $\begin{array}{ll}\text { a. } & \text { Kecerdasan emosi } \\
& (\mathrm{x} 1) \\
\text { b. } & \text { Sikap budaya } \\
& \text { organisasi (x2) } \\
\text { c. } & \text { OCB (Y) }\end{array}$ & $\begin{array}{l}\text { Pada variabel sikap budaya } \\
\text { organisasi responden cenderung } \\
\text { memiliki afeksi yang positif, } \\
\text { terhadap budaya organisasi. } \\
\text { Korelasi antara sikap budaya } \\
\text { organisi dan OCB memiliki } \\
\text { hubungan yang positif dan } \\
\text { signifikan }\end{array}$ & $\begin{array}{l}\text { Analisis regresi } \\
\text { berganda }\end{array}$ \\
\hline 2. & $\begin{array}{l}\text { Pengaruh variabel } \\
\text { budaya } \\
\text { organisasi, } \\
\text { komitmen dan } \\
\text { kepuasan kerja } \\
\text { terhadap OCB } \\
\text { Pegawai }\end{array}$ & $\begin{array}{l}\text { Brahmasari } \\
(2008)\end{array}$ & 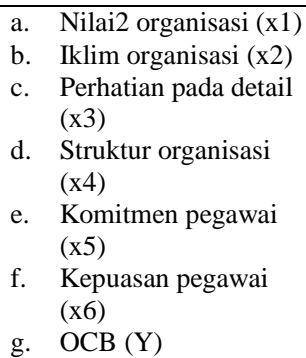 & $\begin{array}{l}\text { Pada } 3 \text { variabel BO (iklim, nilai } \\
\text { dan struktur organisasi) hanya } \\
\text { iklim organisasi yang memiliki } \\
\text { pengaruh yang signifikan terhadap } \\
\text { OCB. Namun secara simultan } \\
\text { memiliki pengaruh yang signifikan } \\
\text { terhadap OCB. }\end{array}$ & $\begin{array}{l}\text { Analisis regresi } \\
\text { berganda }\end{array}$ \\
\hline 3. & $\begin{array}{l}\text { Pengaruh budaya } \\
\text { organisasi, } \\
\text { kemampuan kerja, } \\
\text { komitmen } \\
\text { terhadap OCB } \\
\text { pegawai } \\
\text { BAPPEDA kota } \\
\text { Pekanbaru }\end{array}$ & $\begin{array}{l}\text { Oemar } \\
(2013)\end{array}$ & $\begin{array}{ll}\text { a. } & \text { Budaya Organisai } \\
& (\mathrm{X} 1) \\
\text { b. } & \text { Kemampuan kerja } \\
& (\mathrm{X} 2) \\
\text { c. } & \text { OCB }(\mathrm{Y})\end{array}$ & $\begin{array}{l}\text { Secara simultan dan parsial } \\
\text { variable budaya organisasi, } \\
\text { kemampuan kerja dan komitmen } \\
\text { organisasi berpengaruh positif } \\
\text { terhadap OCB }\end{array}$ & $\begin{array}{l}\text { Analisis regresi } \\
\text { berganda }\end{array}$ \\
\hline 4. & $\begin{array}{l}\text { Pengaruh tingkat } \\
\text { kecerdasan emosi } \\
\text { dan sikap pada } \\
\text { BO terhadap } \\
\text { OCB pegawai } \\
\text { kantor pelayanan } \\
\text { perizinan terpadu } \\
\text { kab. Sukoharjo }\end{array}$ & Jalil (2011) & $\begin{array}{ll}\text { a. } & \text { Kecerdasan emosi } \\
& (\mathrm{x} 1) \\
\text { b. } & \text { Sikap BO (x2) } \\
\text { c. } & \text { OCB (Y) }\end{array}$ & $\begin{array}{l}\text { Untuk sikap pada BO mempunyai } \\
\text { pengaruh yang negatif dan tidak } \\
\text { signifikan terhadap OCB, namun } \\
\text { secara simultan (kecerdasan emosi } \\
\text { dan sikap BO) mempunyai } \\
\text { pengaruh yang signifikan terhadap } \\
\text { OCB. }\end{array}$ & $\begin{array}{l}\text { Analisis regresi } \\
\text { berganda }\end{array}$ \\
\hline 5. & $\begin{array}{l}\text { The Effect of } \\
\text { Organizational } \\
\text { Culture } \\
\text { On Lecturers' Job } \\
\text { Satisfaction and } \\
\text { Performance } \\
\text { (A Research in } \\
\text { Muhammadiyah } \\
\text { University } \\
\text { throughout East } \\
\text { Java) }\end{array}$ & $\begin{array}{l}\text { Sangadji } \\
(2013)\end{array}$ & $\begin{array}{ll}\text { a. } & \text { Organizational } \\
& \text { Culture } \\
\text { b. } & \text { Job Satisfaction } \\
\text { c. } & \text { Performance }\end{array}$ & $\begin{array}{l}\text { Ada pengaruh positif dan } \\
\text { signifikan dari BO terhadap } \\
\text { kinerja melalui kepuasan kerja } \\
\text { secara simultan. }\end{array}$ & Analisis SEM \\
\hline
\end{tabular}

Berdasarkan literature review dan konsep teori yang digunakan maka disusun Hipotesis penelitian sebagai berikut:
H1: Profesionalisme memiliki pengaruh yang positif terhadap Organizational Citizenship Behavior (OCB)

$\mathrm{H} 2$ : Jarak dari manajemen memiliki pengaruh yang positif terhadap 


\section{Organizational Citizenship Behavior (OCB)}

H3: Percaya pada rekan kerja memiliki pengaruh yang positif terhadap Organizational Citizenship Behavior (OCB)

H4: Keteraturan memiliki pengaruh yang posistif terhadap Organizational Citizenship Behavior (OCB)

H5: Permusuhan memiliki pengaruh yang positif terhadap Organizational Citizenship Behavior (OCB)

H6: Integrasi memiliki pengaruh yang positif terhadap Organizational Citizenship Behavior (OCB)

H7: Profesionalisme, jarak dari manajemen, percaya pada rekan kerja, keteraturan, permusuhan dan integrasi secara simultan memiliki pengaruh yang positif terhadap Organizational Citizenship Behavior (OCB)

\section{METODE PENELITIAN}

Jenis Penelitian

Berdasarkan tingkat eksplanasinya penelitian ini digolongkan dalam penelitian asosiatif. Menurut Sugiyono (2012:6) penelitian asosiatif merupakan penelitian yang bertujuan untuk mengetahui pengaruh ataupun juga hubungan antara dua variabel atau lebih.

Objek dan Lokasi Penelitian

Yang menjadi objek pada penelitian ini adalah karyawan pada Rumah Sakit Umum Citra Bunda Medical Centre yang berlokasi di Jl. Proklamasi No.37, Padang.

Jenis dan Teknik Pengumpulan Data

Jenis data yang digunakan adalah data primer dan data sekunder. Dalam penelitian ini metode survey dilakukan dengan menggunakan kuesioner yang disebarkan secara langsung dan wawancara.

Uji Instrumen Penelitian

1. Uji Validitas

Uji validitas digunakan untuk mengukur sah atau tidak sahnya suatu kuesioner.
Kuesioner dikatakan valid apabila pertanyaan pada kuesioner mampu mengungkap sesuatu yang akan diukur oleh kuesioner itu (Ghozali, 2006:45).

Untuk uji validitas digunakan alat uji Factor Analysis (FA) dengan bantuan SPSS for windows versi 17. Menurut Hair et al (1998), factor loading lebih besar \pm 0.30 dianggap memenuhi level minimal, sangat disarankan besarnya factor loading adalah \pm 0.40 , jika factor loading suatu item pertanyaan mencapai \pm 0.50 atau lebih besar maka item tersebut sangat penting dalam menginterprestasikan konstruk yang diukurnya. Pedoman umum untuk analisis faktor adalah nilai lambda atau factor loading $\geq 0.40$ (Ferdinand, 2002).

\section{Uji Reliabilitas}

Pengertian reliabilitas pada dasarnya adalah sejauh mana hasil suatu pengukuran dapat dipercaya. Untuk mengetahui kuesioner tersebut sudah reliable akan dilakukan pengujian reliabilitas kuesioner. Metode pengambilan keputusan pada uji reliabilitas biasanya menggunakan batasan 0,6 yang artinya suatu variabel dikatakan reliable jika nilai Alpha cronbach lebih besar dari 0,6.

Tekhnik Analisis Data

1. Uji Asumsi Klasik

Pada penelitian dilakukan multivariat terhadap model persamaan regresi agar memenuhi persyaratan. Secara teoritis, suatu model akan menghasilkan nilai parameter model penduga yang baik bila dipenuhi asumsi klasik regresi yaitu asumsi normalitas dan heterokedasitas.

2. Analisis Deskriptif Analisis ini digunakan untuk melihat gambaran secara umum tentang variabel yang diteliti dengan langkah verifikasi data dan menghitung nilai jawaban.

3. Analisis Regresi Linier Beganda Alat analisis regresi berganda adalah suatu analisis yang digunakan oleh peneliti, bila peneliti bermaksud meramalkan bagaimana keadaan (naik turunnya) variabel dependen, bila dua 
atau lebih variabel independent sebagai faktor prediktor

4. Koefisien Determinasi

Uji ini digunakan untuk mengetahui seberapa besar sumbangan pengaruh variabel independen (Variabel bebas) terhadap variabel dependen (variabel tidak bebas). Dimana nilai $\mathrm{R}$ untuk mengatur kecocokan garis regresi.

5. Uji Hipotesis

a. Uji t

Uji t-test merupakan uji statistik bertujuan untuk menguji pengaruh secara parsial antara variable independent terhadap variable dependen dengan mengasumsikan bahwa variabel lain dianggap konstan dengan tingkat kepercayaan sebesar $\alpha=5 \%$,

b. Uji F

Uji $F$ digunakan untuk mengetahui pengaruh variabel bebas secara bersama-sama (simultan) terhadap variabel terikat. Signifikan berarti hubungan yang terjadi dapat berlaku untuk populasi.

\section{PEMBAHASAN}

Setelah dilakukan penelitian pada 177 karyawan dan tenaga medis rumah sakit Citra Bunda Medical Center padang didapat deskriptif responden. Berdasarkan gender, sampel penelitian dengan gender wanita mendominasi sebesar 122 atau $68,9 \%$ dan sisanya $31,1 \%$ atau sebesar 55 orang Pria. Sedangkan berdasarkan masa kerja $36,7 \%$ sampel berada pada masa kerja 0-2 tahun dan 27,9\% berada pada 3-5 tahun. Menurut Organ (1995:89) dalam Zurasaka (2008:46), mengemukakan bahwa gender dan masa kerja mempengaruhi OCB. Wanita lebih memiliki perilaku ekstra role dibandingkan dengan Pria. Berdasarkan masa kerja Hasil Uji Instrumen

Uji Validitas

Uji validitas digunakan untuk mengukur sah atau tidak sahnya suatu instrumen. Butir Instrumen dikatakan valid apabila pertanyaan pada kuesioner mampu mengungkap sesuatu yang akan diukur (Ghozali, 2006:45).

Untuk uji validitas digunakan alat uji Factor Analysis (FA) dengan bantuan SPSS for windows versi 17. Menurut Hair et al (1998), factor loading lebih besar \pm 0.30 dianggap memenuhi level minimal, sangat disarankan besarnya factor loading adalah \pm 0.40 , jika factor loading suatu item pertanyaan mencapai \pm 0.50 atau lebih besar maka item tersebut sangat penting dalam menginterprestasikan konstruk yang diukurnya. Pedoman umum untuk analisis faktor adalah nilai lambda atau factor loading $\geq 0.40$ (Ferdinand, 2002).

Dari tabel dibawah dapat diketahui bahwa hasil perhitungan dari seluruh butir pertanyaan. Pada varibel karakteristik budaya organisasi "profesionalisme" (X1) terdapat pertanyaan yang tidak valid yaitu pada butir pertanyaan ke 3 (X1.3), pada variabel karakteristik budaya organisasi "jarak dari manajemen" (X2) semua pertanyaan dinyatakan valid, variabel karakteristik budaya organisasi "percaya pada rekan" (X3) semua pertanyaan juga dinyatakan valid, pada variabel karakteristik budaya organisasi "keteraturan" (X4) terdapat pertanyaan yang tidak valid pada butir ke 4 dan 5 (X4.31 dan X4.32), pada variabel karakteristik budaya organisasi "permusuhan" (X5) pada butir pertanyaan ke 5 (X5.37) dinyatakan tidak valid, pada variabel karakteristik budaya organisasi "integrasi” (X6) terdapat pertanyaan yang tidak valid pada butir pertanyaan ke 3 (X6.40) dan variabel Organizational Citizenship Behavior (Y) terdapat pertanyaan yang tidak valid yaitu pada butir pertanyaan $3,5,9,10$ dan 17 (OCB3, OCB5, OCB9, OCB10 dan OCB17). Selanjutnya pertanyaan yang tidak valid tidak digunakan untuk analisa selanjutnya, pernyataan dinyatakan tidak valid karena factor loading $<0,40$. 
Tabel 2. Variabel OCB

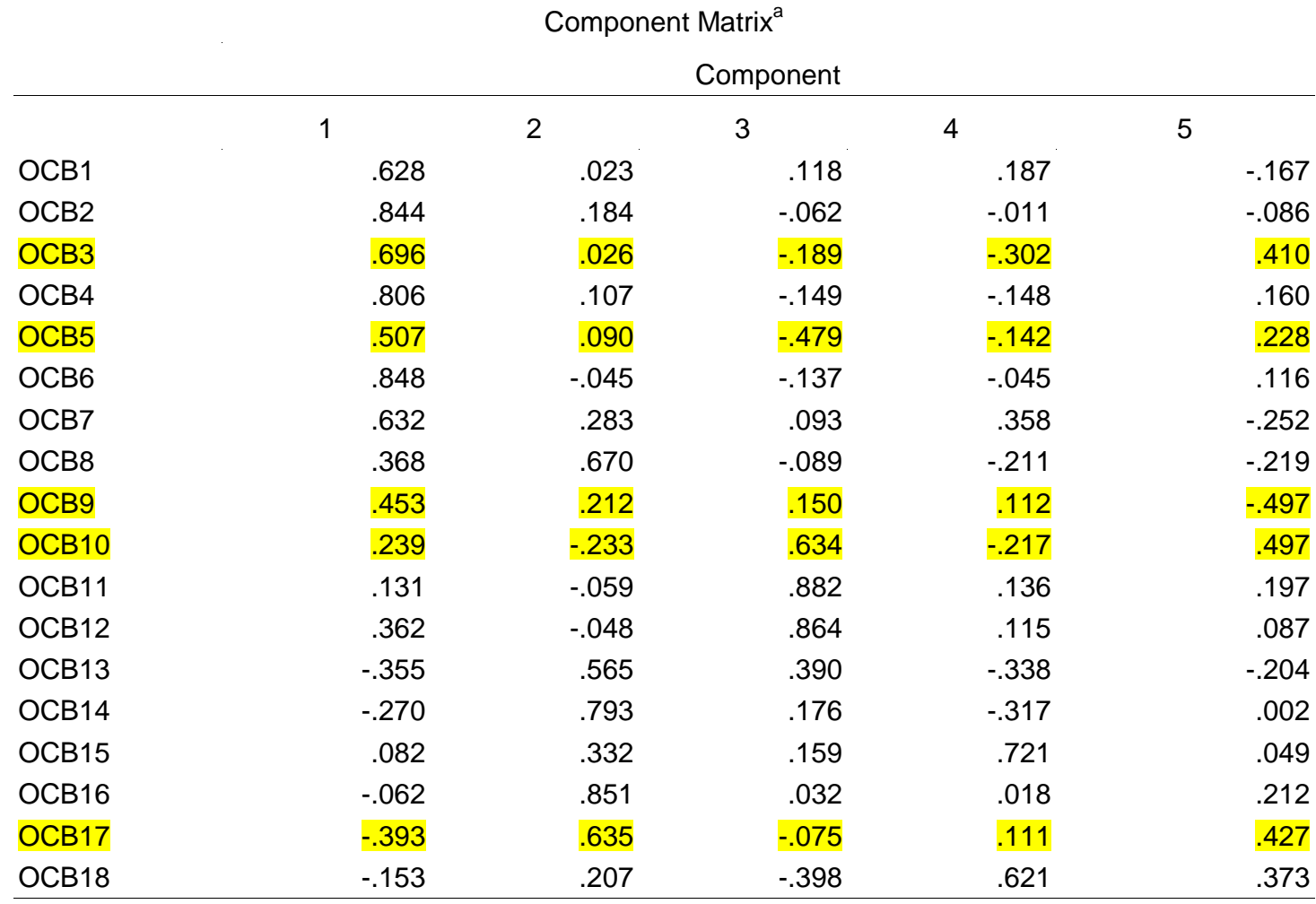

Extraction Method: Principal Component Analysis.

a. 5 components extracted.

Tabel 3. Variabel Karakteristik Budaya Organisasi

\begin{tabular}{|c|c|c|}
\hline \multicolumn{3}{|c|}{ Component Matrix } \\
\hline & Component & Component \\
\hline & 1 & 1 \\
\hline $\mathrm{X} 1.1$ & $.581 \times 3.23$ & .511 \\
\hline $\mathrm{X} 1.2$ & $.450 \times 3.24$ & .822 \\
\hline $\mathrm{X} 1.3$ & $.184 \times 3.25$ & .955 \\
\hline$X 1.4$ & $.596 \times 3.26$ & .951 \\
\hline$X 1.5$ & $.734 \times 3.27$ & .895 \\
\hline $\mathrm{X} 1.6$ & $.435 \times 4.28$ & .820 \\
\hline$X 1.7$ & $.548 \times 4.29$ & .860 \\
\hline$X 1.8$ & $.495 \times 4.30$ & .830 \\
\hline$X 1.9$ & $.670 \times 4.31$ & .397 \\
\hline$X 1.10$ & $.689 \times 4.32$ & .386 \\
\hline $\mathrm{X} 1.11$ & $.591 \times 5.33$ & .893 \\
\hline $\mathrm{X} 1.12$ & $.721 \times 5.34$ & .783 \\
\hline$X 2.13$ & $.479 \times 5.35$ & .903 \\
\hline$X 2.14$ & $.710 \times 5.36$ & .806 \\
\hline$X 2.15$ & $.802 \times 5.37$ & .025 \\
\hline $\mathrm{X} 2.16$ & $.837 \times 6.38$ & .724 \\
\hline $\mathrm{X} 2.17$ & $.732 \times 6.39$ & .783 \\
\hline$X 2.18$ & $.832 \times 6.40$ & .275 \\
\hline $\mathrm{X} 2.19$ & $.632 \times 6.41$ & .576 \\
\hline$X 2.20$ & $.510 \times 6.42$ & .768 \\
\hline $\mathrm{X} 2.21$ & $.603 \times 6.43$ & .778 \\
\hline
\end{tabular}


Tabel 4. Hasil Uji Reliabilitas

\begin{tabular}{lcc}
\hline Variabel & $\begin{array}{c}\text { Cronbach's } \\
\text { Alpha }\end{array}$ & Keterangan \\
\hline Profesionalisme & 0,814 & Baik \\
Jarak dari Manajemen & 0,878 & Baik \\
Percaya pada Rekan Kerja & 0,849 & Baik \\
Keteraturan & 0,842 & Baik \\
Permusuhan & 0,866 & Baik \\
Integrasi & 0,752 & Diterima \\
OCB & 0,673 & Diterima \\
\hline
\end{tabular}

Dari tabel diatas dapat diketahui bahwa rata-rata variabel penelitian memiliki reabilitas yang baik karena nilai Cronbach's Alpha masing-masing variabel dimana pada variabel profesionalisme, jarak dari manajemen, percaya pada rekan kerja, keteraturan dan permusuhan barada pada range $0,8-0,10$ yang merupakan kategori reabilitas baik sedangkan untuk integrasi dan OCB berada pada range $\geq 0,6$ maka merupakan kategori reabilitas diterima.

\section{Tabel 5. Hasil Analisis Regresi Beganda}

\begin{tabular}{llrr}
\hline \multirow{2}{*}{ Model } & & \multicolumn{2}{c}{ Unstandardized Coefficients } \\
\cline { 3 - 4 } 1 & & B & Std. Error \\
& (Constant) & 23.341 & 7.417 \\
& Profesionalisme & .184 & .107 \\
& JrkdariMjmen & .089 & .083 \\
& PrcyaRekan & .467 & .211 \\
& Keteraturan & .093 & .212 \\
& Permusuhan & .526 & .183 \\
& Integrasi & .207 & .216 \\
\hline
\end{tabular}

Berdasarkan tabel diatas maka dapat dibuat persamaan yaitu :

$\mathrm{Y}=23.341+0,184 \mathrm{X} 1+0,089 \mathrm{X} 2+0,467$

$\mathrm{X} 3+0,093 \mathrm{X} 4+0,526 \mathrm{X} 5+0,207+\mathrm{e}$

Dari hasil persamaan regresi di atas dapat diuraikan sebagai berikut:

1. Nilai 23,341 adalah nilai konstanta yang mengindikasi bahwa ketika variabel profesioanlisme (X1), jarak dari manajemen (X2), percaya pada rekan (X3), keteraturan (X4), permusuhan (X5) dan integrasi (X6) dianggap tidak ada maka besarnya OCB (Y) adalah sebesar 23,341. Yang artinya jika Karakteristik Budaya Organisasi (profesionalisme, jarak dari manajemen, percaya pada rekan, keteraturan, permusuhan dan integrasi) tidak ada, karyawan RSU CMBC tetap memilik Organizational Citizenship Behavior (OCB).

2. Nilai 0,184 pada variabel $\mathrm{X} 1$ (profesionalisme) berpengaruh positif terhadap OCB. Dengan kata lain jika variabel profesionalisme meningkat sedangkan variabel lainnya tetap, maka variabel Y (OCB) akan meningkat sebesar 0,184 .

3. Nilai 0,089 pada variabel X2 (jarak dari manajemen) berpengaruh positif terhadap OCB. Hal ini mengandung arti jika variabel jarak dari manajemen meningkat sedangkan variabel lainnya tetap, maka variabel Y (OCB) akan naik sebesar 0,089 . 
4. Nilai 0,467 pada variabel X3 (percaya pada rekan) berpengaruh positif terhadap OCB. Hal ini mengandung arti jika variabel percaya pada rekan meningkat sedangkan variabel lainnya tetap maka variabel Y (OCB) akan mengalami kenaikan sebesar 0,467.

5. Nilai 0,093 pada variabel $\mathrm{X} 4$ (keteraturan) berpengaruh positif terhadap OCB. Hal ini berarti jika variabel keteraturan meningkat dan variabel lainnya tetap maka variabel $\mathrm{Y}$ (OCB) akan mengalami kenaikan sebesar 0,093.
6. Nilai 0,526 pada variabel X5 (permusuhan) berpengaruh positif terhadap OCB. Hal ini mengandung arti jika variabel permusuhan meningkat dan variable lainnya tetap maka variabel Y (OCB) akan mengalami kenaikan sebesar 0,526.

7. Nilai 0,207 pada variabel X6 (integrasi) berpengaruh positif terhadap OCB. Hal ini mengandung arti jika variabel integrasi meningkat dan variabel lainnya tetap maka variabel Y (OCB) akan mengalami kenaikan sebesar 0,207.

Tabel 6. Koefisien Determinasi $\left(\mathbf{R}^{2}\right)$

\begin{tabular}{lccc}
\hline Model & R & R Square & Adjusted R Square \\
\hline 1 & $.321^{\mathrm{a}}$ & .103 & .071 \\
\hline
\end{tabular}

Sumber : Data Primer yang diolah, 2014

Pada tabel 6 dapat dilihat bahwa nilai Adjusted R2 adalah sebesar 0,071. Hal ini dapat diartikan bahwa variabel independent (profesionalisme, jarak dari manajemen, percaya rekan kerja, keteraturan, permusuhan dan integrasi)

\begin{tabular}{lcc}
\hline \multicolumn{1}{c}{ Variabel } & Uji t & Sig \\
\hline Profesionalisme & 1,729 & 0,086 \\
Jarak dari Manajemen & 1,071 & 0,286 \\
Percaya Pada Rekan & 2,211 & 0,028 \\
Keteraturan & 0,437 & 0,662 \\
Permusuhan & 2,872 & 0,045 \\
Integrasi & 0,962 & 0,338 \\
\hline
\end{tabular}

Berdasarkan Tabel diatas, maka hasil uji t pada penelitian ini dapat dijelaskan sebagai berikut:

1. Nilai $t_{\text {hitung pada variabel }}$ profesionalisme adalah 1,729 dengan nilai signifikansi lebih besar dari 0,05 yaitu $0,086(0,086>0,05)$. Dari hasil penelitian didapat bahwa hipotesis pertama ditolak sehingga dapat disimpulkan bahwa variabel profesionalisme tidak berpengaruh signifikan terhadap OCB pada karyawan RSU CBMC Padang.

2. Nilai $t_{\text {hitung }}$ pada variabel jarak dari manajemen adalah 1,071 nilai signifikansi lebih besar dari 0,05 yaitu $0,286(0,286>0,05)$. Dari hasil dapat menjelaskan variabel dependent (OCB) sebesar $7.1 \%$, sedangkan sisanya 92, 9\% diterangkan oleh faktor lain yang tidak diteliti.

Uji Hipotesis

Uji T penelitian didapat bahwa hipotesis kedua ditolak sehingga dapat disimpulkan bahwa variabel jarak dari manajemen tidak mempunyai pengaruh yang signifikan terhadap OCB pada karyawan RSU CBMC Padang.

3. Nilai $t_{\text {hitung }}$ pada variabel percaya pada rekan adalah 2,211 dengan nilai signifikansi lebih kecil dari 0,05 yaitu $0,028(0,028<0,05)$. Dari hasil penelitian didapat bahwa hipotesis ketiga diterima sehingga dapat disimpulkan bahwa variabel percaya pada rekan berpengaruh signifikan terhadap OCB pada karyawan RSU CBMC Padang. 
4. Nilai thitung pada variabel keteraturan adalah 0,437 dan nilai signifikansi lebih besar dari 0,05 yaitu 0,662 $(0,662>0,05)$. Dari hasil penelitian didapat bahwa hipotesis keempat ditolak sehingga dapat disimpulkan bahwa variabel keteraturan tidak berpengaruh signifikan terhadap OCB pada karyawan RSU CBMC Padang

5. Nilai $t_{\text {hitung }}$ pada variabel permusuhan adalah 2,872 dan nilai signifikansi lebih kecil dari 0,05 yaitu $0,045(0,045$ $<0,05)$. Dari hasil penelitian didapat bahwa hipotesis kelima diterima sehingga dapat disimpulkan bahwa variabel permusuhan berpengaruh signifikan terhadap OCB pada karyawan RSU CBMC Padang

6. Nilai $t_{\text {hitung }}$ pada variabel integrasi adalah 0,962 dengan nilai signifikansi lebih besar dari 0,05 yaitu 0,338 $(0,338>0,05)$. Dari hasil penelitian didapat bahwa hipotesis keenam ditolak sehingga dapat disimpulkan bahwa variabel integrasi tidak berpengaruh signifikan terhadap OCB Uji F pada karyawan RSU CBMC Padang.

Dari hasil uji $\mathrm{F}$ pada penelitian ini didapatkan nilai $\mathrm{F}$ hitung sebesar 3,257 dengan angka signifikansi sebesar 0,005. Atas dasar perbandingan tersebut, berarti secara bersama-sama (simultan) profesionalisme, jarak dari manajemen, percaya rekan kerja, keteraturan, permusuhan dan integrasi berpengaruh positif dan signifikan terhadap OCB.

\section{PENUTUP}

Dari hasil uji hipotesis diketahui bahwa variabel X1 (profesionalisme), variable X2 (jarak dari manajemen), variabel X4 (keteraturan) dan variabel X6 (integrasi) tidak berpengaruh signifikan terhadap OCB karyawan RSU CBMC Padang, hanya variabel X3 (percaya pada rekan) dan variabel X5 (permusuhan) yang berpengaruh secara signifikan terhadap OCB karyawan. Namun secara simultan karakteristik budaya organisasi (profesionalisme, jarak dari manajemen, percaya pada rekan, keteraturan, permusuhan dan integrasi) berpengaruh positif dan signifikan terhadap OCB karyawan RSU CBMC Padang.

Dari hasil koefisen determinasi $\left(\mathrm{R}^{2}\right)$ pengaruh karakteristik budaya organisasi (profesionalisme, jarak dari manajemen, percaya pada rekan, keteraturan, permusuhan dan integrasi) karyawan RSU CBMC Padang terhadap OCB karyawan sangat kecil, hanya sebesar $7,1 \%$ sedangkan sisanya $92,9 \%$ dipengaruhi faktor lain yang tidak diteliti.

Penerapan karakteristik budaya organisasi di atas tercermin dalam bentuk membantu rekan kerja, membantu memberikan pelayanan kepada siapapun, bersedia menyelesaikan tugas dan pekerjaan tanpa diminta, mengikuti perubahan dan perkembangan organisasi, tepat waktu dalam melaksanakan aktivitas kerja, keterlibatan dalam fungsi dan kegiatan organisasi, memiliki rasa toleransi, dan tidak mengeluh atas beban pekerjaan yang diberikan. Semakin positif karyawan dalam melaksanakan budaya organisasi yang ada, maka akan semakin meningkat pula OCB karyawan tersebut.

\section{DAFTAR PUSTAKA}

$\underline{10.22202 / \text { economica.2015.v3.i2.259 }}$

Ferdinand, Augusty. 2002. Structural Equation Modeling dalam Penalitian Manajemen. Semarang: Fakultas Ekonomi Universitas Diponegoro

Ghozali, Imam. 2005. Aplikasi Analisi Multivariate dengan Program SPSS, Semarang, Badan Penerbit Universitas Diponegoro, p 41-51, p149-153.

Hatta. 2013. IPM Indonesia 2012 Tempati Ranking 121 di Dunia, www.wartaekonomi.co.id/berita8461/ip m-indonesia-2012-tempati-ranking-121di-dunia.html. Diakses 20 November 2013

Luthans, Fred. 2002. Organizational Behavior. 9th ed., New York: McGraw-Hill.

Markoczy, L dan Xin, K. 2002. The Virtues of Omission in Organizational Citizenship Behavior, ttp://goldmark.org/livia/papers/ocb/o cb.pdf. Diakses 21 November 2013 
